\title{
Return-to-active-duty rates after anterior cervical spine surgery in military pilots
}

\author{
Charles A. Miller, MD, ${ }^{1}$ Jason H. Boulter, MD, ${ }^{1}$ Daniel J. Coughlin, MD, ${ }^{1}$ Michael K. Rosner, MD, ${ }^{2}$ \\ Chris J. Neal, MD, ${ }^{1}$ and Michael S. Dirks, MD ${ }^{1}$ \\ ${ }^{1}$ Section of Neurosurgery, Walter Reed National Military Medical Center, Bethesda, Maryland; and 2Department of Neurosurgery, \\ George Washington University School of Medicine, Washington, DC
}

\begin{abstract}
OBJECTIVE Symptomatic cervical spondylosis with or without radiculopathy can ground an active-duty military pilot if left untreated. Surgically treated cervical spondylosis may be a waiverable condition and allow return to flying status, but a waiver is based on expert opinion and not on recent published data. Previous studies on rates of return to active duty status following anterior cervical spine surgery have not differentiated these rates among military specialty occupations. No studies to date have documented the successful return of US military active-duty pilots who have undergone anterior cervical spine surgery with cervical fusion, disc replacement, or a combination of the two. The aim of this study was to identify the rate of return to an active duty flight status among US military pilots who had undergone anterior cervical discectomy and fusion (ACDF) or total disc replacement (TDR) for symptomatic cervical spondylosis.
\end{abstract}

METHODS The authors performed a single-center retrospective review of all active duty pilots who had undergone either ACDF or TDR at a military hospital between January 2010 and June 2017. Descriptive statistics were calculated for both groups to evaluate demographics with specific attention to preoperative flight stats, days to recommended clearance by neurosurgery, and days to return to active duty flight status.

RESULTS Authors identified a total of 812 cases of anterior cervical surgery performed between January 1, 2010, and June 1, 2017, among active duty, reserves, dependents, and Department of Defense/Veterans Affairs patients. There were 581 ACDFs and 231 TDRs. After screening for military occupation and active duty status, there were a total of 22 active duty pilots, among whom were 4 ACDFs, 17 TDRs, and 2 hybrid constructs. One patient required a second surgery. Six (27.3\%) of the 22 pilots were nearing the end of their career and electively retired within a year of surgery. Of the remaining 16 pilots, $11(68.8 \%)$ returned to active duty flying status. The average time to be released by the neurosurgeon was 128 days, and the time to return to flying was 287 days. The average follow-up period was 12.3 months.

CONCLUSIONS Adhering to military service-specific waiver guidelines, military pilots may return to active duty flight status after undergoing ACDF or TDR for symptomatic cervical spondylosis.

https://thejns.org/doi/abs/10.3171/2018.9.FOCUS18380

KEYWORDS military; pilots; cervical; fusion; arthroplasty

$\mathrm{C}$ ERVICAL spondylosis affects the general population and can be managed both medically and surgically. However, cervical spondylosis can restrict an aviator's military career if their symptoms limit capabilities to function at an optimal level. Untreated cervical spondylosis will ground a pilot for several reasons. First, pain and weakness can be significant distractions and limitations for the pilot, placing them and the military aircraft in a compromised situation. Second, untreated symptoms requiring frequent medical treatment can limit training and deployability and can burden units with pilot shortages. If pilots undergo surgical treatment, they can return to flight status only once a flight waiver is submitted and approved. While there are military service-specific criteria, in general, a waiver is considered for approval if the following criteria are met: there is radiographic fusion after anterior cervical discectomy and fusion (ACDF) or implant stability on flexion-extension plain radiographs after

ABBREVIATIONS ACDF = anterior cervical discectomy and fusion; $C D A=$ cervical disc arthroplasty; $D M D C=$ Defense Manpower Data Center; $G=$ gravitational force; TDR = total disc replacement. 
total disc replacement (TDR), and neurological symptoms have resolved after a minimum 6-month waiting period. At this point, the neurosurgeon recommends that the patient return to unrestricted active duty, and the waiver authority considers approval. Current guidelines state that multilevel ACDF and single-level TDR are not waiverable for ejection-seat aircraft, but flight waivers are approved at the discretion of the flight surgeon and higher command.

The US Air Force has approximately 12,363 active duty pilots; the US Army has 14,000 active, reserve, and National Guard pilots; and the US Navy has 10,250 pilots. ${ }^{9}$ A study by the US Army Aeromedical Research Laboratory documented an incidence of approximately 1 disc herniation per 1000 aviator-years. ${ }^{6}$ That incidence becomes significant when considering that the cost of training an operational US military pilot is roughly $\$ 9$ million. ${ }^{3}$ Therefore, it is in the military's interest to understand the effect that surgically treated cervical spondylosis has on a pilot's ability to return to active duty flight status.

\section{Methods}

We performed a single-center retrospective study to evaluate return-to-duty rates after surgery for cervical spondylosis with or without radiculopathy in an active-duty military pilot population. After obtaining IRB approval, we performed a search for "anterior cervical fusion" and "total disc replacement" in our surgical scheduling system database. Patients were de-identified and separated into active duty and non-active duty groups. Data including age, rank, branch of service, military occupation, and date of retirement were compiled by the Defense Manpower Data Center (DMDC). Our active-duty pilot population was identified based on the military occupation code generated by the DMDC data report. A retrospective chart review was then completed for each patient to obtain preoperative flight status, type of aircraft flown (rotary or fixed wing), type of surgery (ACDF vs TDR), type of disc implant, levels of surgery, days to neurosurgery-recommended clearance for return to active duty, days for waiver authority clearance for active duty flight status, initiation of medical waiver or documentation of return to flying, surgery length, and follow-up period.

\section{Results}

Between January 1, 2010, and June 1, 2017, a total of 812 cases of cervical spondylosis were treated by 9 different neurosurgeons within the neurosurgery division at the Walter Reed National Military Medical Center. There were 581 ACDFs and 231 TDRs. Based on the military occupation code generated by the DMDC report, there were a total of 39 active duty pilots. After excluding aircrew members and already retired pilots at the time of surgery, there were 22 active duty pilots who had undergone ACDF or TDR (Table 1). Within this active duty group, there were 21 men and 1 woman, with an average age of 41.7 years at the time of surgery. Grouped according to military branch, the study population was $59.1 \%$ Army, 27.3\% Navy/Marine Corps, and 13.6\% Air Force, with $72.7 \%$ of the pilots operating rotary wing aircraft. Preoperatively, 15 (68.2\%) of the 22 pilots were grounded for
TABLE 1. Summary of preoperative characteristics

\begin{tabular}{cc}
\hline \multicolumn{1}{c}{ Characteristic } & Value \\
\hline No. of pilots & 22 \\
\hline Mean age at op in yrs (range) & $41.7(32.7-52.5)$ \\
\hline Sex, no. (\%) & $21(95.5)$ \\
\hline Male & $1(4.5)$ \\
\hline Female & \\
\hline Rank, no. (\%) & $9(40.9)$ \\
\hline CW2-4 & $4(18.2)$ \\
\hline O1-3 & $9(40.9)$ \\
\hline O4-6 & $13(59.1)$ \\
\hline Service, no. (\%) & $6(27.3)$ \\
\hline Army & $3(13.6)$ \\
\hline Navy/Marine Corps & $6(27.3)$ \\
\hline Air Force & $16(72.7)$ \\
\hline Aircraft, no. (\%) & \\
\hline Fixed wing & $12(54.5)$ \\
\hline Rotary & $10(45.5)$ \\
\hline Tobacco use, no. (\%) & \\
\hline Yes & \\
\hline No & \\
\hline
\end{tabular}

medical management and evaluation for cervical spondylosis, whereas the remaining 7 (31.8\%) were grounded for other reasons in addition to cervical spondylosis.

Of the 22 active duty pilots, 4 underwent ACDF, 17 underwent TDR, and 2 had hybrid constructs, for a total of 23 cases (Table 2). There were 17 single-level constructs: 3 ACDFs and 14 TDRs. There was 1 two-level C5-7 ACDF, 2 contiguous two-level C5-7 TDRs, 1 noncontiguous twolevel TDR, and 2 three-level hybrid constructs. In terms of arthroplasty type, a total of 5 Bryan implants (Medtronic), 9 Prestige implants (Medtronic), 3 Prestige LP implants (Medtronic), and 1 ProDisc-C implant (DePuy) were placed. Level C5-6 (48.3\%) was the most commonly involved level, followed by C6-7 (41.4\%), C3-4 (6.9\%), and C4-5 (3.4\%). The average length of ACDF surgery was 86 minutes with an average blood loss of $31 \mathrm{ml}$. The average length of TDR surgery was 85 minutes with an average blood loss of $24 \mathrm{ml}$. The average follow-up period with neurosurgery was 12.3 months. The average length of documented follow-up with the flight surgeon after return to an active flight status was 1.9 years.

Only one pilot had two surgeries within our military hospital. He had two noncontiguous TDRs (C3-4, C6-7). He returned to active flight duty but required a C5-6 ACDF 3 years later for adjacent-segment disease and retired within a year of his second surgery. Another pilot had undergone a prior C4-7 ACDF at a civilian hospital and was approved for a flight waiver but developed neck pain a year later. He had pseudarthrosis at C6-7 and underwent a C6-7 TDR at our hospital. He was approved for a waiver for a nonejection fixed wing aircraft. ${ }^{11}$

Six pilots $(27.3 \%)$ retired within a year of surgery, two of whom became commercial pilots. Five pilots who were 
TABLE 2. Operative summary

\begin{tabular}{|c|c|}
\hline Parameter & No. $(\%)$ \\
\hline Total cases & 23 \\
\hline \multicolumn{2}{|l|}{ ACDF } \\
\hline Total & 4 \\
\hline 1-level & $3(13)$ \\
\hline 2-level & $1(4.3)$ \\
\hline \multicolumn{2}{|l|}{ TDR } \\
\hline Total & 17 \\
\hline 1-level & $14(60.9)$ \\
\hline 2-level & $3(13.0)$ \\
\hline Hybrid & $2(8.7)$ \\
\hline \multicolumn{2}{|l|}{ Implant } \\
\hline Total & 18 \\
\hline Prestige & $9(50)$ \\
\hline Prestige LP & $3(16.7)$ \\
\hline Bryan & $5(27.8)$ \\
\hline ProDisc-C & $1(5.6)$ \\
\hline \multicolumn{2}{|l|}{ Level } \\
\hline Total & 29 \\
\hline C3-4 & $2(6.9)$ \\
\hline C4-5 & $1(3.4)$ \\
\hline C5-6 & $14(48.3)$ \\
\hline C6-7 & $12(41.4)$ \\
\hline \multicolumn{2}{|l|}{ Complication } \\
\hline Total & 2 \\
\hline Cervicalgia & $1(3.4)$ \\
\hline Adjacent-segment disease & $1(3.4)$ \\
\hline Pseudarthrosis* & $1(3.4)$ \\
\hline
\end{tabular}

* Initial surgery done at civilian hospital.

ineligible for retirement never returned to active flying duty. Of these five, three failed to meet the medical requirements for symptoms other than cervical spondylosis; two of these three proceeded to medical evaluation boards for separation. The remaining two pilots were not granted flight waivers for symptoms related to cervical spondylosis. One had residual arm weakness that did not improve with surgery, and the other had persistent cervicalgia requiring alternative therapies.

Excluding those 6 pilots retiring within a year of surgery, $11(68.8 \%)$ of the remaining 16 returned to active flight duty (Table 3). If the 3 pilots who failed to return to active flight duty for reasons other than cervical spondylosis are also excluded, then the return rate to active flight duty actually increases to $84.6 \%$ (11 of 13). Twenty (90.9\%) of the 22 pilots were recommended for return to unrestricted active duty by the neurosurgeon.

For the entire group, the average time to be recommended for return to active duty by the neurosurgeon was 128 days. For those pilots who returned to active flight duty, the average time for neurosurgeon approval was 138 days and the average time for return to active flight duty was 287 days. Of those who returned to active flight duty,
TABLE 3. Summary of results

\begin{tabular}{cc}
\hline \multicolumn{1}{c}{ Parameter } & Value \\
\hline $\begin{array}{c}\text { Recommended for unrestricted active } \\
\text { duty by neurosurgeon }\end{array}$ & 20 of $22(90.9 \%)$ \\
\hline Retired w/in 1 yr of op & 6 of $22(27.3 \%)$ \\
\hline Did not return to flight status & 5 of $22(22.7 \%)$ \\
\hline CS-related DQ & 2 of $5(40 \%)$ \\
\hline Non-CS-related DQ & 3 of $5(60 \%)$ \\
\hline RTFS & 11 of $22(50 \%)$ \\
\hline RTFS w/o retiring pilots & 11 of $16(68.8 \%)$ \\
\hline RTFS w/o retiring pilots \& non-CS DQ & 11 of $13(84.6 \%)$ \\
\hline
\end{tabular}

$\mathrm{CS}=$ cervical spondylosis; $\mathrm{DQ}=$ disqualification; RTFS = return to flight status.

2 had single-level ACDF, 7 had single-level TDR, 1 had a two-level noncontiguous TDR, and 1 had a prior $\mathrm{C} 4-7$ ACDF converted to a C6-7 TDR hybrid construct due to pseudarthrosis at the C6-7 level (Table 4). One patient suffered persistent cervicalgia after surgery, and one required additional surgery for adjacent-segment disease; otherwise, there were no surgical complications.

\section{Illustrative Cases}

\section{Case 1}

This active duty F-35 pilot presented with a 3-year history of intermittent left $\mathrm{C} 6$ radiculopathy with an acute exacerbation resulting in paresthesias in the C6 dermatome. Electromyography confirmed a C6 radiculopathy, and MRI showed moderate to severe left C5-6 foraminal stenosis. An uncomplicated C5-6 ACDF was completed, with a resolution of symptoms at the 5-month postoperative check (Fig. 1). The pilot was cleared by the neurosurgeon at 155 days and returned to flying duties at 481 days.

\section{Case 2}

This active duty UH-60 (Blackhawk) pilot presented with a third exacerbation of left $\mathrm{C} 7$ radiculopathy with associated numbness. Magnetic resonance imaging demonstrated a disc bulge causing severe canal stenosis at the left C6-7 foramen. A C6-7 TDR (Prestige LP) was completed after conservative management had failed (Fig. 2). After neurosurgery clearance, the pilot returned to flight status at 185 days.

\section{Discussion}

Cervical spondylosis with or without radiculopathy is a common problem among the active-duty military population with an incidence of 1.79 cases per 1000 person-years. ${ }^{10}$ Several studies have documented an increased rate of cervical spondylosis within the aviation community. Helicopter pilots are subjected to prolonged levels of whole-body vibration and often have poor ergonomics with weighted gear and helmets. Accumulated flight hours in helicopter pilots have been associated with increased degenerative changes of the cervical spine. ${ }^{2}$ Fixed wing pilots are also affected by the weighted performance gear and flight helmets but are exposed to positive gravitational (+Gx, Gy, 
TABLE 4. Characteristics of patients with successful return to flight duty

\begin{tabular}{llllccll}
\hline Rank & Op & Levels & Implant & $\begin{array}{c}\text { Time to NSGY } \\
\text { Recommendation (days) }\end{array}$ & $\begin{array}{c}\text { Time to } \\
\text { RTFD (days) }\end{array}$ & $\begin{array}{c}\text { Rotary or } \\
\text { Fixed Wing }\end{array}$ & Aircraft \\
\hline O3 & ACDF & C5-6 & PEEK & 155 & 481 & Fixed wing & F-35 \\
\hline O3 & ACDF & C6-7 & PEEK & 106 & 187 & Rotary & CH-53E (Super Stallion) \\
\hline O4 & TDR & C3-4, C6-7 & Prestige & 173 & 201 & Rotary & AH-64 (Apache) \\
\hline O3 & TDR & C6-7 & Prestige & 133 & 134 & Rotary & AH-1 (Cobra) \\
\hline O2 & TDR & C5-6 & Prestige & 103 & 110 & Rotary & UH-60 (Blackhawk) \\
\hline CW2 & TDR & C5-6 & Prestige & 145 & 708 & Rotary & AH-64 (Apache) \\
\hline CW4 & Hybrid & C4-7 (C4-6 ACDF, C6-7 TDR) & Prestige & 89 & 103 & Fixed wing & C-12 \\
\hline CW4 & TDR & C6-7 & Bryan & 90 & 113 & Rotary & AH-64 (Apache) \\
\hline CW4 & TDR & C6-7 & Prestige LP & 181 & 185 & Rotary & UH-60 (Blackhawk) \\
\hline O4 & TDR & C5-6 & Prestige & 242 & 584 & Fixed wing & B-52 \\
\hline O6 & TDR & C6-7 & Prestige LP & 101 & 357 & Rotary & MV-22 (Osprey) \\
\hline
\end{tabular}

NSGY = neurosurgery; PEEK = polyetheretherketone; RTFD = return to flight duty.

$\mathrm{Gz}$ ) forces that may accelerate disc degeneration. . $^{1,2,4,8,13} \mathrm{~A}$ 1996 study found that 7.4\% of US Army aviators were removed from flight status due to cervical and lumbar herniated discs. ${ }^{6}$ While the symptoms of cervical spondylosis may not severely limit the average individual's career, they are significant for military pilots. Radicular pain, paresthesias, numbness, and weakness can be significant distractors to pilots, slowing their reaction time or making some required emergency procedure undoable. Axial neck pain can limit cervical motion preventing pilots from effectively surveying their aerial surroundings, and recurrent doctor visits for medical care can detract from their training time or mission. ${ }^{12}$ Symptomatic relief alone from ACDF or TDR is not enough to return to active duty flight status. The change in normal spinal physiology after ACDF or TDR must also be considered in active duty pilots. The additional stress placed on adjacent joints could be significant in high-performance aircraft in which pilots are subjected to significant Gx-, Gy-, and Gz-forces. The additional stress can be minimal during routine flying, but during combat maneuvers or ejections, pilots can be subjected to upwards of 12-14 +Gz-forces. With poor positioning, vertebral column fractures can occur at $10 g .{ }^{12}$ While ejection seats attempt to pull the vertebral column into proper alignment via shoulder harnesses, the mobile cervical spine is outside of the harness system and therefore not as protected. ${ }^{12}$ Thus, there is concern for significant neurological injury from hardware failure in multilevel cervical constructs.

Each branch of military service has similar flight waiver criteria for cervical spondylosis with slight variations in terminology and restrictions. The Air Force waiver guide for herniated nucleus pulposus and spinal fusion was last updated in March 2016. The Air Force requires single-level cervical spine fusions to have a minimum waiting period of 6 months after surgery. Waivers are granted only if symptoms have completely resolved with no neurological symptoms, there is evidence of bony fusion, and a neurosurgeon has cleared the pilot for return to duty without restrictions. Total disc replacements must show stability on flexion-extension radiographs. Currently, multilevel cervical fusions are not waiverable for ejection seat aircraft. ${ }^{12}$
The Navy waiver guide was last updated in April 2016. Cervical radiculopathy treated with ACDF is considered for waiver approval if after 6 months postoperatively there is complete resolution of symptoms, radiographs demonstrate healing, and there is no instability on flexion-extension radiographs. Single-level ACDF can be granted waivers for both rotary wing and ejection seat aircraft. Multilevel ACDFs or single-level TDR can be granted a waiver for rotary wing or non-ejection seat aircraft. ${ }^{18}$

The Army waiver guide, last updated in 2014, considers waivers after surgery if symptoms have resolved, if the surgeon has approved a return to normal duties, if there are no residual motor/sensory/reflex deficits, and there is no instability of posterior elements. The Army guide states that TDRs are not waiverable, but there have been select cases for which a waiver has been granted. While the Army guide does not specify a time period, Army Aviation has typically operated under the 6-month waiting period as dictated by the Air Force and Navy. ${ }^{17}$ The 6-month waiting period is intended to allow fusion of the ACDF to occur, but it has been incorporated for disc arthroplasty as well.

To maintain the fighting force, the US military places tremendous importance on unit and individual medical readiness. It is invaluable for unit commanders to understand the short- and long-term consequences a surgical procedure has on the readiness of an aviator. In addition, it is our professional duty as military surgeons to counsel the aviator on the risks and benefits of a surgical procedure as well as the realistic expectations of the effects that surgery may have on his or her military career. In recent years, return-to-active-duty rates for cervical spondylosis after TDR or ACDF have been reported but have not been broken down by military occupation. In 2010, Tumialán et al. reported on TDR with the ProDisc-C implant in a military population. ${ }^{16}$ The average time to return to full unrestricted active duty among the cervical arthroplasty group was 10.3 weeks, compared to 16.5 weeks in a matched ACDF control group. This was a small study with 12 patients in each group, but the authors concluded that arthroplasty is comparable to arthrodesis and can 


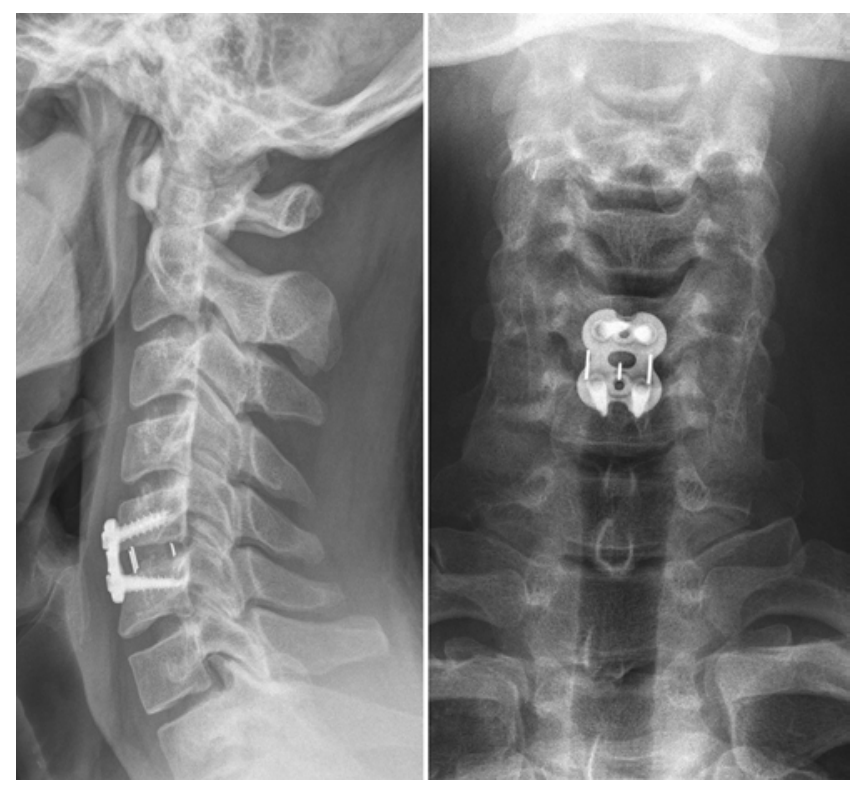

FIG. 1. Lateral (left) and anteroposterior (right) plain radiographs showing appropriate placement of C5-6 ACDF.

help expedite return to active duty. More recently, in June 2018, Tumialán et al. published results on 132 single- and two-level ACDFs with a total return-to-active-duty rate of $88 \%$ at a mean of 15.2 weeks. ${ }^{15}$ While they evaluated rank as a variable, they did not stratify by military occupation. In another large study in 2010, Tracey et al. evaluated the outcomes of 259 patients who had undergone cervical disc arthroplasty (CDA) compared to ACDF at a single military treatment facility. ${ }^{14}$ In the CDA group 132 patients were active duty, and in the ACDF group 40 patients were active duty. The return-to-active-duty rate in the CDA group was $92.4 \%$ compared to $84 \%$ in the ACDF group. Time to return to active duty was not reported, and rank and occupation were not stratified.

It is important to distinguish between the aviation community and the rest of the military because the criteria to return to active duty for aviators are more stringent and mandate the presence of radiographic fusion in the ACDF population.,12,18 To our knowledge, this is the first study to demonstrate the rate of return to active duty flight status among military pilots following anterior cervical surgery for cervical spondylosis with either ACDF or TDR. A previous study out of Lackland Air Force Base in 1964 reported on 5 pilots who returned to flying after anterior cervical fusion, but no other details were provided. ${ }^{7}$ Our data show that of the 22 pilots on active duty, $11(50 \%)$ returned to active duty flight status. If we exclude the pilots nearing retirement and those who failed to obtain waivers for symptoms other than cervical spondylosis, then the return to active duty flight status is actually $84.6 \%$. This rate is similar to the $90.9 \%$ neurosurgeon clearance rate for return to active duty. No pilots were granted waivers if the neurosurgeon did not first recommend approval to return to active duty. These data are important for military providers and unit commanders when discussing the implications of grounding a pilot

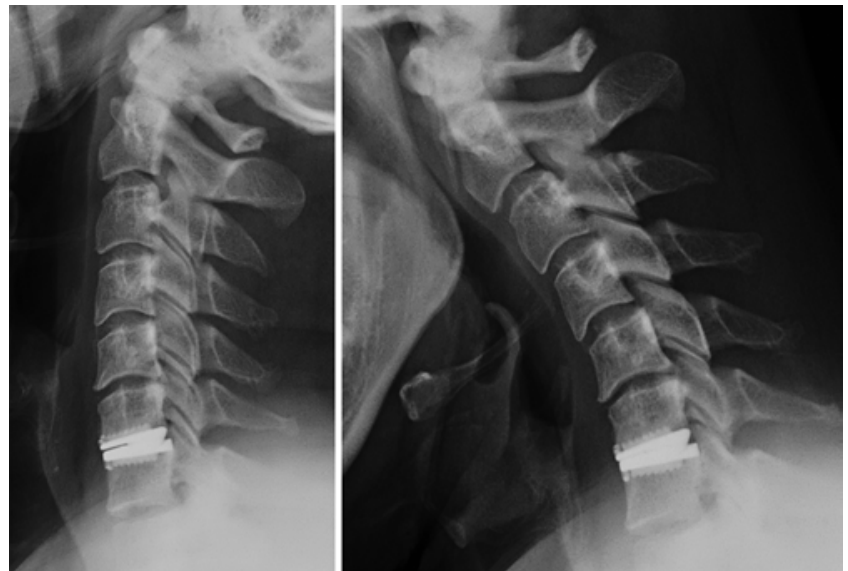

FIG. 2. Lateral plain radiographs demonstrating appropriate placement and stability of a C6-7 Prestige LP implant on extension (left) and flexion (right).

and the potential to return to active duty flight status after surgical treatment.

The retrospective nature, limited follow-up time, and small size of our study limit our ability to apply its results to the entire pilot population. The retrospective review may introduce selection bias by limiting our population to only those pilots who were discovered in our study design. The follow-up time of 12.3 months is similar to the follow-up of 9-14 months in previous return-to-duty studies. ${ }^{5,14-16}$ Note that the 12.3 months is the follow-up time with the neurosurgeon and does not reflect the follow-up with the flight surgeon who saw the pilot regularly. After the neurosurgeon recommended return to unrestricted active duty, the pilot would see the neurosurgeon only on referral from the flight surgeon or if there were hardware complications. We also acknowledge the small sample size as a limitation, although it does reflect the uniqueness of this population. Currently, the recommendation to return to flight status after ACDF or TDR is based on expert opinion because of the relatively low number of active duty pilots undergoing ACDF or TDR and the inability to generalize previously published return-to-duty rates in nonpilot populations. Long-term data are needed to better understand the rate of adjacent-segment disease or construct failure when exposed to the typical occupational hazards, such as Gx-, Gy-, and Gz-forces; poor ergonomics; weighted gear; or prolonged whole-body vibrations. These occupational hazards likely lead to an increased incidence of cervical spondylosis but not until late into a pilot's career and oftentimes near retirement. Thus, longterm data on active duty pilots not nearing retirement can be difficult to obtain. While our operative outcomes and return-to-duty rates appear similar to those in previous studies, our surgeons may be more likely to recommend return to unrestricted active duty because of the greater number of pilots we see at our medical center and the lack of data showing a negative impact on a pilot's career after anterior cervical surgery. There have been no reported catastrophic failures of cervical constructs as a result of flying maneuvers or ejections in this study population or 
in the reported literature. Additionally, our data are only as good as the physician's ability to document accurate submission of flight waiver and/or clearance for active duty flight status. Nevertheless, this is the largest reported cohort of active duty pilots undergoing ACDF or TDR for cervical spondylosis. Our data confirm that pilots affected by cervical spondylosis can be safely treated with surgery and return to active duty flight status. We hope our results assist the consulting surgeon and unit commander in counseling their aviators and provide clearer expectations for individual and unit medical readiness.

\section{Conclusions}

Military pilots may have higher rates of cervical spondylosis than the general population, and their operative management must be tailored to their occupational waiver guide to ensure return to active duty flight status. Previous studies have published rates of return to active duty of $80 \%-90 \%$ but have not stratified based on military occupation. To our knowledge, this is the first study to demonstrate the return-to-duty rates among US military pilots who have had ACDF, TDR, or hybrid construct. If we exclude pilots nearing retirement and those failing to meet medical requirements for waiver approval for symptoms other than cervical spondylosis, then the rate of return to active duty flight status after anterior cervical surgery in our military pilot population was $84.6 \%$. Return to duty for military aviators after anterior cervical surgery for cervical spondylosis appears to be safe. Additionally, return to duty appears to be the most likely outcome for the majority of military aviators. As advocates for our patients and stewards of military resources, we as military neurosurgeons should use this information to coordinate surgical plans with patients, flight surgeons, and commanders with the aim of keeping pilots flying in order to maintain the fighting strength of our armed forces.

\section{References}

1. Aydoğ ST, Türbedar E, Demirel AH, Tetik O, Akin A, Doral MN: Cervical and lumbar spinal changes diagnosed in fourview radiographs of 732 military pilots. Aviat Space Environ Med 75:154-157, 2004

2. Byeon JH, Kim JW, Jeong HJ, Sim YJ, Kim DK, Choi JK, et al: Degenerative changes of spine in helicopter pilots. Ann Rehabil Med 37:706-712, 2013

3. General Accounting Office: Military Personnel Actions Needed to Better Define Pilot Requirements and Promote Retention. Washington, DC: GAO, 1999

4. Hämäläinen O, Vanharanta H, Kuusela T: Degeneration of cervical intervertebral disks in fighter pilots frequently exposed to high $+\mathrm{Gz}$ forces. Aviat Space Environ Med 64:692-696, 1993

5. Lunsford JG, Lawson BK, Johnson AE, Topp RF: Return to duty rates in active duty service members after elective surgery of the lumbar spine. Mil Med 181:572-576, 2016

6. Mason KT, Harper JP, Shannon SG: Herniated nucleus pulposus: rates and outcomes among U.S. Army aviators. Aviat Space Environ Med 67:338-340, 1996

7. Myers PW: Disc disease in flying personnel. Aerosp Med 35:65-68, 1964

8. Newman DG: +GZ-induced neck injuries in Royal Australian Air Force fighter pilots. Aviat Space Environ Med 68:520524,1997
9. Parrish K: Congress probes military pilot shortage. DoD News. March 30, 2017 (https://dod.defense.gov/News/Article/ Article/1135200/congress-probes-military-pilot-shortage/) [Accessed October 10, 2018]

10. Schoenfeld AJ, George AA, Bader JO, Caram PM Jr: Incidence and epidemiology of cervical radiculopathy in the United States military: 2000 to 2009. J Spinal Disord Tech 25:17-22, 2012

11. Spinelli J, Neal CJ, Rosner MK: Performance of cervical arthroplasty at a pseudoarthrosed level of a multilevel anterior cervical discectomy and fusion: case report. Mil Med 181:e621-e624, 2016

12. Syoc DV: Herniated nucleus pulposus (HNP) and spinal fusion. Air Force Waiver Guide. (https://www.wpafb.af.mil/ Portals/60/documents/711/usafsam/USAFSAM-WavierGuide-171005.pdf) [Accessed October 10, 2018]

13. Taneja N: Spinal disabilities in military and civil aviators. Spine (Phila Pa 1976) 33:2749-2753, 2008

14. Tracey RW, Kang DG, Cody JP, Wagner SC, Rosner MK, Lehman RA Jr: Outcomes of single-level cervical disc arthroplasty versus anterior cervical discectomy and fusion. J Clin Neurosci 21:1905-1908, 2014

15. Tumialán LM, Ponton RP, Cooper AN, Gluf WM, Tomlin JM: Rate of return to military active duty after single and 2-level anterior cervical discectomy and fusion: a 4-year retrospective review. Neurosurgery [in press], 2018

16. Tumialán LM, Ponton RP, Garvin A, Gluf WM: Arthroplasty in the military: a preliminary experience with ProDisc-C and ProDisc-L. Neurosurg Focus 28(5):E18, 2010

17. US Army: Intervertebral disc disease. Flight Surgeon's Aeromedical Checklist. 2014

18. US Navy: Intervertebral disc disease. U.S. Navy Aeromedical Reference and Waiver Guide. (https://www.med. navy.mil/sites/nmotc/nami/arwg/Documents/WaiverGuide/ Complete_Waiver_Guide.pdf) [Accessed October 10, 2018]

\section{Disclaimer}

The views expressed in this article are those of the author and do not reflect the official policy of the Department of Army/Navy/ Air Force, Department of Defense, or US government.

\section{Disclosures}

Dr. Rosner has been a consultant for Medtronic and Atec.

\section{Author Contributions}

Conception and design: Miller, Rosner, Neal, Dirks. Acquisition of data: Miller, Boulter, Coughlin, Rosner. Analysis and interpretation of data: all authors. Drafting the article: Miller, Boulter, Coughlin, Neal, Dirks. Critically revising the article: all authors. Reviewed submitted version of manuscript: all authors. Approved the final version of the manuscript on behalf of all authors: Miller. Statistical analysis: Miller, Boulter, Coughlin, Neal, Dirks. Administrative/technical/material support: Miller.

\section{Supplemental Information}

\section{Previous Presentations}

Portions of this work were accepted for a poster presentation at the Congress of Neurological Surgeons Annual Meeting held in Houston, Texas, on October 6-10, 2018.

\section{Correspondence}

Charles A. Miller: Walter Reed National Military Medical Center, Bethesda, MD. charles.a.miller408.mil@mail.mil. 